\title{
Four in 10 US people fear large outbreak of Ebola
}

\author{
Michael McCarthy \\ Seattle
}

Despite reassurances from health officials that there is little chance of a large outbreak of Ebola virus disease in the United States, four in 10 people there are concerned that there will be, a new survey shows. A quarter fear that they or someone in their family might fall ill with it in the next year, it found. ${ }^{1}$

As at 22 August, more than 1200 people have died in the current Ebola outbreak in west Africa. Two infected US missionaries were transported home for treatment but have since been discharged from hospital and are recovering.

In response to the survey, which was conducted by Harvard School of Public Health and SSRS (a polling company), 39\% of a nationally representative sample of US adults said they were concerned there would be a large outbreak of Ebola virus disease inside the US in the next 12 months, and 26\% said they were concerned that they or someone in their immediate family might get sick from it in the next 12 months.

Respondents with less education were more likely to be concerned about an outbreak, with $50 \%$ of those who had not finished high school saying they were concerned, compared with $24 \%$ of those with a college degree.
Although health officials have noted that the Ebola virus is not easily spread in the community, requiring contact with infected patients, animals, or contaminated objects, such as syringes, $68 \%$ of those surveyed said that they believed the virus was spread easily.

Furthermore, $33 \%$ of respondents said they believed there was an effective drug to treat the infection, and $45 \%$ said that there was no effective drug.

Gillian Steel Fisher, deputy director of the Harvard Opinion Research Program, said the survey's findings indicated that "the media and public health officials need to better inform Americans of Ebola and how it is spread."

The poll of 1025 adults was conducted 13-17 August 2014.

thebmj.com Feature: Ebola: an opportunity for a clinical trial? (BMJ 2014;349:g4997, doi:10.1136/bmj.g4997)

Harvard School of Public Health. Ebola poll topline. Aug 2014. www.hsph.harvard.edu/ news/wp-content/uploads/sites/21/2014/08/ebola_Topline_final_08-20-14.pdf.

Cite this as: BMJ 2014;349:95321

๑ BMJ Publishing Group Ltd 2014 